\title{
University of Ulster FireSERT's New Laboratories
}

\section{INTRODUCTION}

In 1997 a major investment programme to upgrade the infrastructure of the Universities in the U.K. was introduced. The Joint Infrastructure Fund (JIF) initiative supported by U.K. Government Departments, the Wellcome Trust, Research Councils and Higher Education Funding Councils resulted in a $£ 750 \mathrm{~m}$ fund. Bids to the fund were made on a competitive basis. In funding round III FireSERT's bid for $£ 5.7 \mathrm{~m}$ was one of only 28 successful bids from 600 applications.

\section{THE NEW LABORATORIES}

The design of the laboratories commenced in November 2000 and the new building was handed over and occupied by FireSERT in March 2002. Plate No. 1 shows a general view of the building which comprises a large burn hall, fire dynamics laboratory, human behaviour in fire laboratory, offices and ancillary accommodation. A feature of the burn hall is the $18 \mathrm{~m}$ high external walls which have been constructed as diaphragm walls. The diaphragm walls are fitted with adjustable louvres to provide the airflow of air into the burn hall necessary for any fire burning under the large hood, plates 2 and 3 . New equipment installed include state of the art furnaces which facilitates study of wall/floor, column/beam connections subjected to thermal insult, plate 4 section. The fire dynamics laboratory is equipped with medium to bench scale equipment including a $2 \mathrm{~m} \times 2 \mathrm{~m}$ calorimeter. Two free standing bespoke cone calorimeter pods are also included to facilitate particular programmes of research. The human behaviour suite includes three fully instrumented sleeping rooms which are used to determine the responses of sleepers to fire cues. In addition floor space is available in which to construct particular environmental settings, offices, restaurants, etc. and pursue human behaviour in fire related studies.

All of the equipment installed in the new FireSERT laboratories is controlled via a control room constructed and instrumented for the purpose.

Complimenting the experimental fire research facilities is a new dedicated fire modelling suite equipped with state of the art hardware.

In addition to the new laboratories FireSERT is recruiting scientists and engineers to take forward and progress its expanding research portfolios. The developments at FireSERT University of Ulster position FireSERT to contribute more to the international development of fire safety science/engineering. 